as regards their sanitary condition and the effect upon the public healtb; and it was upon the strength of the reports thus furnished him that he decided to take the step which he did. According to the city statutes now in force, the head of the Department of Street Cleaning is removable by the mayor, provided such removal meets with the approval of the Board of Health, whenever the mayor shall certify that to his judgment such removal is required in the public interest. It is needless to say that in the present instance when Mayor Grant had certified to this effect the Health Board promptly gave its approval of the removal of the Commissioner.

The new incumbent of the position, Mr. Thomas S. Brennan, who, it is believed, will conscientiously and thoroughly carry out the work he is paid to do, is a man with an exceptionally large experience in the administration of the charitable and criminal institutions of the city. Also, it may be stated, he has an exceptionally large acquaintance among the nedical profession of New York, with many of the most prominent of whom he came in constant contact for a long period of years. This career in many respects is an interesting one. In $18_{59}$, at the early age of 16 , he was appointed a night watchman at the Bellevue Hospital, and was soon promoted to the captain of the watch and night storekeeper. He was next transferred to Charity Hospital, on Blackwell's Island, where he became steward and deputy warden. In I 866 he was made warden of Bellevue Hospital, in which capacity he remained until 1875 , when he was appointed one of the Commissioners of Charities and Correction; a position which he held contiuuously for fourteen years and eight months. These commissioners, it will be remembered, have charge of the affairs of all the hospitals, asylums, prisons, and other charitable and penal institutions belonging to the city.

Sanitary superintendent Wm. A. Ewing, who has just returned from abroad where he has been making a study of the sanitary methods in vogue in some of the principal cities, expresses the opinion that while the streets of New York are certainly kept as clean as those of most of the latter, so far as our sanitary regulations in general are concerned we are far in advance of any of the European cities he visited. The plumbing in the hotels and public buildings here, he says, is eminently superior to anything of the kind abroad, and our supervision and care of contagious diseases, he also states, are the very best that he has seen anywhere. While in London Dr. Ewing attended the International Congress of Hygiene and Demography, and he found that the exhibits sent by the New York Health Department were by far the largest and best there. He took with him to the Congress and placed on exhibition plans of the plumbing and drainage, and of the lighting and ventilation of some of the best tenement houses here, as well as the plans of older tenement houses which had been altered in order to improve their sanitary condition; and these plans excited so much interest among the sanitary engineers and architects present that at their request for more time to examine the exhibits he left them in London for a week after the close of the Congress.

There has lately been brought to this city a remarka- ble case of parasitic growth, the subject of which, born in India, is known as the double bodied Hindoo boy. A number of physicians and others were invited to a private inspection of the lad at the Metropolitan Hotel, and Dr. George D. Bleything has made the following report concerning him: "I have examined the boy Laloo in the presence of Dr. W. G. Thompson, of the New York Crniversity Medical School, Dr. J. Blake White, of Charity Hospital, and number of medical gentlemen and representatives of leading newspapers and medical periodicals, and find him to be a remarkable case of arrested development in fotal life. The boy himself is a fine, bright, well developed youth of eighteen years, snd attached to the extremity of his sternum is the incomplete figure of a twin. The arms are given out, without scapulæ, from the sternum of the young man. The trunk is short and incomplete, but it terminates in a pelvis with which the legs are connected. There would seem to be no separate heart in the parasite, and the pulse, both radical and axillary, is synchronous with that of the autosite. There is anchylosis of the joints in the undeveloped child. The young man is conscious of a sensation when this second body is roughly touched." It is said to be the opinion of competent surgeons who have examined the boy, that the parasitic growth could be removed without serious injury to him; but in that case his value as a museum "freak," which is now very great, would, of course, collapse. As it is, he does not appear to suffer much inconvenience from his unsightly incumbrance, and he is very agile in his movements.

P. B. 1 .

\section{Illinois Army and Navy Medical Associa-} tion.

Editor fournal of Am. Med. Assoc'n.-At the meeting of the Army and Navy Medical Association, held in Chicago, October 7 th and Sth, the following resolution was offered and unanimously adopted, viz.:

WHEREAS, In view of our high esteem for Dr. John H. Rauch, as a medical officer of the United States Army during the war of the Rebellion, as a gentleman of worth and culture, and for his most efficient services as a member of the Illinois State Board of Health, whereby the sanitary conditions of the State and Nation have been greatly improved, the standard of medical education elevated, and the interests of profession and people most thoroughly guarded, therefore,

Resolved, 'That we hereby express our regret that so efficient a member of the Board of Health of the State of Illinois, should have retired from that body. No more active, efficient, earnest worker, can be found among the medical profession, to fill that important position, and we believe that the interests of the people as well as those of the medical profession, will be advanced by his recall to duty thereon. Very respectfully,

EDWARD P. BARTLETT, Secretary.

Springfield, Ill., October $14^{\text {th, }}$ ISgr.

\section{Lost Papers.}

Editor A. M. A. Journal, 68 Wabash Ave., Chicago, Ill.

Dear Sir:-On yesterday the clerk of the Maxwell House here, handed me a package of papers, which proved to be the rotes and original papers read in the Section of Practice of Medicine, at the meeting of the Association held at this place in May, ISso. They evi- 